\title{
Development of morphology tuned SnS hierarchical structures for enhanced photosensitive photodiode fabrication
}

\section{N. Abhiram}

PSG Institute of Technology and Applied Research

\section{R. Marnadu}

PSG Institute of Technology and Applied Research

\section{S. Gunasekaran}

Sri Ramakrishna Mission Vidyalaya College of Arts and Science

\section{Santhana}

PSG Institute of Technology and Applied Research

\section{J. Chandrasekaran}

PSG Institute of Technology and Applied Research

\section{N.S.M.P. Latha Devi}

Koneru Lakshmaiah Education Foundation

D Thangaraju ( $\nabla$ dthangaraju@gmail.com )

PSG Institute of Technology and Applied Research https://orcid.org/0000-0003-1928-3779

\section{Research Article}

Keywords: Hierarchical structure, oleic acid, photodiode, I-V characteristics, photo response

Posted Date: March 2nd, 2021

DOl: https://doi.org/10.21203/rs.3.rs-260149/v1

License: (c) (i) This work is licensed under a Creative Commons Attribution 4.0 International License.

Read Full License

Version of Record: A version of this preprint was published on July 1st, 2021. See the published version at https://doi.org/10.1016/j.inoche.2021.108623. 
Development of morphology tuned SnS hierarchical structures for enhanced photosensitive photodiode fabrication

\section{N. Abhiram, ${ }^{1,2}$ R. Marnadu, ${ }^{3}$ S. Gunasekaran, ${ }^{1}$ V. Santhana, ${ }^{1}$ J. Chandrasekaran, ${ }^{3}$} N.S.M.P. Latha Devi, ${ }^{2}$ D. Thangaraju, ${ }^{1,2 *}$

${ }^{1}$ nano-crystal Design and Application Lab (n-DAL), Department of Physics, PSG Institute of Technology and Applied Research, Avinashi road, Neelambur, Coimbatore, Tamilnadu 641062, India.

${ }^{2}$ Department of Physics, Koneru Lakshmaiah Education Foundation, Vaddeswaram, AP, India.

${ }^{3}$ Department of Physics, Sri Ramakrishna Mission Vidyalaya College of Arts and Science, Coimbatore 641 020, Tamil Nadu, India.

*Corresponding author

E-mail: dthangaraju@gmail.com (Dheivasigamani Thangaraju) 


\begin{abstract}
Hierarchical structure transformation and surface modification of solvothermal method synthesized $\mathrm{SnS}$ with oleic acid in ethylene glycol solvent were discussed in detail. The structural, optical, and morphology of as prepared SnS samples were examined by X-ray diffraction (XRD), Raman Spectroscopy, and Field Emission Scanning Electron Microscopy (FE-SEM). XRD verifies the orthorhombic crystal structure of the $\mathrm{SnS}$ phase for all synthesized samples. Single-phase nature of synthesized particles was confirmed with Raman characterization. Morphology evolution of $\mathrm{SnS}$ from regular to hierarchical structures upon adding oleic acid is performed through FE-SEM analysis. Junction diodes p-SnS/n-Si fabricated with different oleic acid concentrations $(0.5,1.5$, and $2.5 \mathrm{~mL})$ synthesized $\mathrm{SnS}$ particles show better photo-response, which can be used in photodiode applications.
\end{abstract}

Keywords: Hierarchical structure; oleic acid; photodiode; I-V characteristics; photo response. 


\section{Introduction}

Single-phase metal chalcogenide synthesis using the hydrothermal method is still challenging because of their growth behaviour at high temperatures. Maintain stoichiometric in a harsh environment while growing metal chalcogenide is complicated and always ended in multiple phases. Suitable solvent and combination of surfactant can be the solution for controlling multiple phases in metal chalcogenide [1].

Non-oxide semiconducting materials such as metal chalcogenides and nitrides are the most attractive materials due to their potential properties such as good light-sensor, visiblelight-driven catalysis, and suitable band gap for high-end sensing applications [2]. Semiconducting materials with low and narrow bandgap with layered chalcogenides materials attract researchers to develop various energy application fields like supercapacitors, lithiumion batteries, and electrical and optoelectrical devices [3-5]. Due to its high durability and cost-effectiveness, abundant in nature, and the synthesis of nontoxic semiconducting materials at the nano range is very easy [6]. From metal chalcogenides, $\mathrm{SnS}$ is one of the potential materials with a narrow bandgap, excellent absorption, eco friendly, cost effective, earth-abundant are the properties to make the $\mathrm{SnS}$ nanomaterial to construct useful optoelectronic device application [7-10]. Generally, SnS possess an orthorhombic crystal structure with double-layered formation, and bonding between $\mathrm{Sn}$ and $\mathrm{S}$ is light because of Van der Waals forces [11-12]. Tin sulfide has different phases like $\mathrm{SnS}, \mathrm{Sn}_{2} \mathrm{~S}_{3}, \mathrm{SnS}_{2}, \mathrm{Sn}_{3} \mathrm{~S}_{4}$, and $\mathrm{Sn}_{4} \mathrm{~S}_{5}$ with a different stoichiometric ratio of tin and sulfur [13]. These different phases of SnS are possibly prepared with several methods like wet-chemical, co-precipitation and hydrothermal [14-19]. Among them, the hydrothermal method is preferred to synthesis single-phase SnS nanostructure with different particle morphology. SnS capable of possessing both p-type and n-type semiconducting nature corresponds to the element of tin and changing the synthesis conditions of $\mathrm{SnS}$. These materials have day light photocatalytic nature for 
applying dyes degradation applications due to their mobility of charge carriers upon photon strike [20]. Various structure of $\mathrm{SnS}$ material widely in various applications such as holographic recording, photovoltaic material, catalyst for hydrogen production, anode material in Li-Ion batteries, photocatalyst, photodetector, photoelectrochemical cells, Drug delivery, and dye synthesized solar cell [21-29]. In recent years, chalcogenides, semiconducting materials with different doping materials were extensively reported, and the results show the improvement in the photo-sensing nature of the optoelectronic devices. Cost effective photodetector based on $\mathrm{SnS}$ nanoparticle which is synthesised by chemical deposition method with sensitivity of $202 \%$ is reported by M.S. Mahdi et. al. which expose better photo response behaviour [30]. High performance photodetector based on ultrathin SnS nanobelts was developed by X. Zhou et. al. using physical vapor deposition method and which have quantum efficiency of $4.65 \times 10^{4} \%$ and spectral detectivity of $6 \mathrm{x}$ $10^{9}$ jones for light sensor application [31].

In this work, an attempt has been made to fabricate surface tuned $\mathrm{SnS}$ hierarchical structure using different oleic acid concentrations with ethylene glycol solvent. Synthesized SnS particles were used to fabricate $\mathrm{p}-\mathrm{SnS} / \mathrm{n}$-Si diodes using the solution-processed dropcasting method and the photo responsive parameters such as ideality factor (n), barrier height $\left(\Phi_{\mathrm{B}}\right)$, photoresponsivity $(\mathrm{R})$, photosensitivity $\left(\mathrm{P}_{\mathrm{S}}\right)$, quantum efficiency $(\mathrm{QE}) \%$, specific detectivity $\left(\mathrm{D}^{*}\right)$ calculated and discussed in detail. The excellent photo response and photosensitivity of the surfactant tuned $\mathrm{SnS}$ are proposed for flexible photodetector application.

\section{Materials and Methods}

\subsection{Materials}


Stannous chloride dihydrate $\left(\mathrm{SnCl}_{2} .2 \mathrm{H}_{2} \mathrm{O}, \sim 99 \%\right.$, SRL India), thioacetamide $\left(\mathrm{CH}_{3} \mathrm{CSNH}_{2}, \sim 99 \%\right.$, LOBA Chemie, India), ethylene glycol $\left(\mathrm{C}_{2} \mathrm{H}_{6} \mathrm{O}_{2}, \sim 98 \%\right.$, Spectrum Reagents) and oleic acid $\left(\mathrm{C}_{18} \mathrm{H}_{34} \mathrm{O}_{2}, \sim 65 \%\right.$, SRL India) were purchased for synthesis of $\mathrm{SnS}$ and the reagents were used as purchased form.

\subsection{Synthesis of SnS particles}

The solvothermal method has been adopted for the synthesis of SnS hierarchical structures. $\mathrm{SnCl}_{2} .2 \mathrm{H}_{2} \mathrm{O}(1 \mathrm{mmole})$ and $\mathrm{CH}_{3} \mathrm{CSNH}_{2}(1 \mathrm{mmole})$ were dissolved in $30 \mathrm{~mL}(\mathrm{~A})$ and $10 \mathrm{~mL}$ (B) ethylene glycol, respectively. Both A and B solutions were ultrasonicated for complete precursor dissolution and further stirred for $30 \mathrm{~min}$. The final solution was loaded into $100 \mathrm{~mL}$ Teflon lined autoclave, and the temperature was raised to $175^{\circ} \mathrm{C}$. The fixed temperature was maintained for 6hours to facilitate the reaction. Then, obtained solution cool down to ambient temperature further centrifuge for separation of the synthesized sample then the collected precipitate were rinsed with ethanol twice for eliminating the impurities. The above procedure was followed for oleic acid, included synthesis as mentioned, and different oleic acid concentrations $(0.5,1.5$, and $2.5 \mathrm{~mL})$ are added to the mixed solution.

\subsection{Diode fabrication}

The silicon $(\mathrm{Si})$ substrate with n-type nature with the dimension of $(1 \mathrm{x} 1 \mathrm{~cm})$ with $\sim 260( \pm 30) \mu \mathrm{m}$ thickness and resistivity of $\sim 40-50( \pm 5) \Omega / \mathrm{cm}$ are the specification of the substrate used in the diode construction. Before coating, the substrate was washed with a piranha solution $\left(\mathrm{H}_{2} \mathrm{O}_{2}: \mathrm{H}_{2} \mathrm{SO}_{4}:: 2: 1\right)$ for eliminating the organic, metallic impurities and oxidized layer on $\mathrm{n}$-Si wafer surface. The above-washed substrate was ultrasonicated with distilled water as a sequenced process. Synthesized pure and oleic acid assisted $\mathrm{SnS}$ (40 mg) was dispersed in cyclohexane $(1 \mathrm{~mL})$ with a drop of oleic acid. By drop-casting technique, the formed $\mathrm{SnS}-$ oleic acid solution was coated on the $\mathrm{n}-\mathrm{Si}$. The fabricated layer was annealed at 
$220^{\circ} \mathrm{C}$ for sixty minutes to remove excess oleic acid. Silver glue (ELTECK) was applied on either sides to make the good ohmic contact for diode performance characterization. The schematic diagram of $\mathrm{SnS}+$ oleic acid based diode is presented in Fig.1.

\subsection{Characterization techniques}

Powder X-Ray diffraction (XRD) was performed to investigate structural properties of synthesized pure and oleic acid-assisted SnS sample (RINT-2200 X-ray diffractometer (source- $\mathrm{CuK} \alpha$ with wavelength of $\lambda=1.54178$ ). Raman spectral analysis is performed for synthesized powders through Confocal Raman Microscope with AFM imaging (WiTec alpha 300, Germany) with $532 \mathrm{~nm}$ excitation. SnS particle morphology was examined and recorded by Scanning electron microscope (SEM) ZEISS EVO 18 model. The photodiode parameters were analysed through the Keithley (6517-B) source meter in dark and light conditions with a portable PEC-L01 solar simulator.

\section{Results and discussion}

\subsection{Structural analysis}

The comparative diffraction patterns of pure SnS and SnS particle synthesized with different oleic acid concentrations $(0.5,1.5$, and $2.5 \mathrm{~mL})$ were shown in Fig. 2. The recorded patterns are well-matched with standard JCPDS file no 00-014-0620, and there are no impurities observed. The prepared $\mathrm{SnS}$ is in orthorhombic nature with space group of Pbnm and lattice parameters of $\mathrm{a}=4.32, \mathrm{~b}=11.19, \mathrm{c}=3.97 \AA$. The strong diffraction patterns show the good crystallinity of the prepared samples. The high peak intensity observed at $2 \theta=31.43$, which is matched along with the (111) plane, is the preferential orientation of orthorhombic SnS. Some other less intense peaks observed with (120), (131), (141), and (042) also confirm the formation of $\mathrm{SnS}$ nanostructure with combinational morphology like sheets and hierarchical 
structures [32]. Variation in intensity of synthesized samples is shown in Fig. 3., which reveals the impact of surfactant concentration on the $\mathrm{SnS}$ material.

\subsection{Raman analysis}

Raman analysis carried for pure $\mathrm{SnS}$ and particles synthesized with different proportions of oleic acid, shown in Fig. 4. The characteristics of Raman peaks confirm the formation of the $\mathrm{SnS}$ material. The observed Raman mode at $76 \mathrm{~cm}^{-1}$ is attributed to the $\mathrm{B}_{1 \mathrm{~g}}$ mode, which is purely belongs to $\mathrm{SnS}$ phase [33]. The peak at $98 \mathrm{~cm}^{-1}$ is presented for the $\mathrm{Ag}$ mode which arises due to the $\mathrm{Sn}$ and $\mathrm{S}$ atoms' inter atomic vibration in $\mathrm{SnS}$ lattice. Another peak found at $158 \mathrm{~cm}^{-1}$ is assigned to the $\mathrm{B}_{2 \mathrm{~g}}$ mode of the $\mathrm{SnS}$. The observed broad peak at $187 \mathrm{~cm}^{-1}$ and a tiny bump near $212 \mathrm{~cm}^{-1}$ are assigned for $\mathrm{Ag}$ mode of $\mathrm{SnS}$ nanoparticle, and such results confirm the formation of $\mathrm{SnS}$ [34]. The observed result from Raman analysis is consistent with the XRD pattern.

\subsection{Surface morphology}

The particle morphology of synthesized pure and different oleic acid included $\mathrm{SnS}$ was analyzed by FESEM and recorded micrographs are compared in Fig. 5(a-h). When increasing the concentration of oleic acid, the $\mathrm{SnS}$ is changed from average to dense hierarchical patterns. The evolution of the hierarchical flower-like structure of $\mathrm{SnS}$ concerning the increased volume of oleic acid in ethylene glycol is presented in Fig. 5(a-b), which reveals that there are no hierarchical patterns formed in the particle without oleic acid in the synthesis. A small amount of oleic acid $(0.5 \mathrm{~mL})$ changes the morphology of $\mathrm{SnS}$ into a hierarchical flower. The flat flakes composed of flower structure of $\mathrm{SnS}$ with $0.5 \mathrm{~mL}$ oleic acid are shown in Fig. 5(c-d). Further increase of oleic acid concentration as $1.5 \mathrm{~mL}$, the spherical hierarchical flower-like structure of $\mathrm{SnS}$ was formed and is shown in Fig. 5(e-f). At $2.5 \mathrm{~mL}$ oleic acid, the spherical hierarchical structure of $\mathrm{SnS}$ is comprised of primary and 
secondary particles and is shown in Fig. 5(g-h). Different morphology of the particles may be a reason for the enhancing photo-sensing nature of the sensing layer.

\subsection{I-V characterization}

The current-voltage studies of the constructed diodes are carried under light and dark conditions. The forward and reverse current measurement varied from -3 to $+3 \mathrm{~V}$ was shown in Fig. 6. The I-V studies confirm better sensing of the diodes fabricated by SnS based material on incident light. The rise in values of current are exponential to voltage upon lighting indicates photo-conducting behaviour of $\mathrm{p}-\mathrm{SnS} / \mathrm{n}-\mathrm{Si}, \mathrm{p}-\mathrm{SnS}+$ Oleic acid $(0.5 \mathrm{~mL}) / \mathrm{n}$ $\mathrm{Si}, \mathrm{p}-\mathrm{SnS}+$ Oleic acid $(1.5 \mathrm{~mL}) / \mathrm{n}-\mathrm{Si}$, and p-SnS + Oleic acid $(2.5 \mathrm{~mL}) / \mathrm{n}-\mathrm{Si}$. Semi-logarithmic plot of ln (J) vs V of fabricated diode was depicted in Fig. 7. Based on thermionic emission theory, the diode's current transport mechanism is explained by the following equation [35].

$\mathrm{I}=\mathrm{I}_{0}\left[\exp \left(\frac{\mathrm{q}\left(\mathrm{V}-\mathrm{IR}_{\mathrm{S}}\right)}{\mathrm{nK}_{\mathrm{B}} \mathrm{T}}\right)-1\right]$

Here,

$I_{0}=A A^{*} T^{2} \exp \left(-\frac{q \phi_{B}}{K_{B} T}\right)$

The Ideality factor $(\mathrm{n})$ is calculated from the following equation [36].

$\mathrm{n}=\frac{\mathrm{q}}{\mathrm{k}_{\mathrm{B}} \mathrm{T}}\left(\frac{\mathrm{d}(\mathrm{V})}{\mathrm{d}(\ln (\mathrm{I}))}\right)$

The Barrier height $\left(\Phi_{\mathrm{B}}\right)$ is expressed from the following equation [37].

$\Phi_{\mathrm{B}}=\frac{\mathrm{K}_{\mathrm{B}} \mathrm{T}}{\mathrm{q}} \operatorname{In}\left(\frac{\mathrm{AA}^{*} \mathrm{~T}^{2}}{\mathrm{I}_{0}}\right)$

here $\mathrm{q}, \mathrm{V}, \mathrm{K}_{\mathrm{B}}, \mathrm{T}, \mathrm{A}, \mathrm{A}^{*}$, and Io stands for a charge, voltage, Boltzmann constant, temperature, diode area, Richardson constant, and reverse saturation current, correspondingly. The $\mathrm{n}$ value is changed from 2.0 to 12.7 in dark conditions, and under the light condition, it is varied from 
3.4 to 6.7 . The value $n$ should be unity $(n=1)$ for ideal diode, the observed values for $n$ is $>1$, which attributed to non-ideal nature of the current diode [31]. The reason is inhomogeneity of the film surface, diffusion current, and oxide layer. The value of barrier height was changed from 0.70 to $0.83 \mathrm{eV}$ in dark conditions and under light conditions 0.67 to $0.77 \mathrm{eV}$. In p-type semiconductors such as $\mathrm{SnS}$, the majority charge carrier will be represented by holes that increase photocurrent generation in the sensing layer by absorbing the free electron by the absorption oxygen molecules. The same trend was observed, and the results confirm the good high light/dark current ratio of $\mathrm{SnS}$ based diodes applicable for photodetector application [38].

\subsection{Photodetector analysis}

Photosensitive parameters such as photoresponsivity $\left(\mathrm{P}_{\mathrm{S}}\right)$, responsivity $(\mathrm{R})$, external quantum efficiency (EQE), and specific detectivity (D*) of fabricated devise are compared in Table.1. The photodiode parameters are essential factors to evaluate the fabricated photodiode's performance, which are calculated from following equations [39].

$$
\begin{aligned}
& P_{S}(\%)=\frac{I_{P h}-I_{D}}{I_{D}} \times 100 \\
& R=\frac{I_{P h}}{P A} \\
& E Q E=\frac{R h c}{q \lambda} \\
& D^{*}=\frac{R}{\left(2 q I_{D}\right)^{1 / 2}}
\end{aligned}
$$

here $\mathrm{I}_{\mathrm{Ph}} / \mathrm{I}_{\mathrm{D}}, \mathrm{A}, \mathrm{P}, \mathrm{h}, \mathrm{c}$, and $\lambda$ are photo/dark current, diode illuminated area, lamp irradiation, Planck's constant, light speed, and source wavelength. The comparative plot of photosensitivity parameters vs. Voltage of fabricated diode was presented in the Fig. 8. The photosensitivity of the fabricated diodes is changed from 7018.02 to $63095.6 \%$, where p-SnS 
+ Oleic acid $(1.5 \mathrm{~mL}) / \mathrm{n}-\mathrm{Si}$ is attain the maximum photo response. The photoresponsivity $(\mathrm{R})$ varied from 22.5 to $73.75(\mathrm{~mA} / \mathrm{W})$ and the maximum responsivity observed for pure $\mathrm{SnS}$ based photodiode which is the ratio between photocurrent and unit power of incident photons. The high photoresponsivity may due to the surface-volume ratio of hierarchical structures and it results in efficient light absorption. It may cause an increase in the photogenerated electronhole pair in the sensing layer; this leads to the high photoresponsivity of the $\mathrm{SnS}$ based photodiode. The low-density traps also contribute to high responsivity, which diffuses the charge carriers [31]. It is found that the responsivity decreases with increasing the surfactant concentration. It may be the electron insufficient in excitation in the energy band because of the surfactant concentration. The external quantum efficiency (EQE) of the photodiode is given by equation (7) and maximum EQE value obtained for pristine $\mathrm{SnS}$ based photodiode resulted in $28.5 \%$, which shows the efficiency of gain in the detector. The specific detectivity is an important parameter that characterizes the detector's sensitivity nature and measures the signal-to-noise ratio given by expression (8). The photodetection performance of the diode depends on the spectral detectivity value. The value of the specific detectivity changed from $1.01 \times 10^{11}$ to $1.78 \times 10^{11}$ jones, which infers that the increase in the surfactant with $\mathrm{SnS}$ influences the value of specific detectivity. The $\mathrm{p}-\mathrm{SnS}+$ Oleic acid $(1.5 \mathrm{~mL})$ based diode has a higher value of $\mathrm{D}^{*}$ compared with other diodes. The obtained result is higher than the previously reported value of $\mathrm{SnS}$ based photodiode $[40,41]$. From the result, $\mathrm{SnS}+$ oleic acid are a suitable material for optoelectronic device application.

\section{Conclusion}

Morphology tuned hierarchical SnS structures were successfully fabricated through the hydrothermal method with different concentrations of oleic acid in ethylene glycol solvent. The XRD results show that the $\mathrm{SnS}$ is highly crystalline without impurity reflections. The Raman results confirm the phase purity of $\mathrm{SnS}$ with well-identified Raman 
peaks. The tuned hierarchical structures of $\mathrm{SnS}$ with increased concentration of oleic acid were clearly observed in FESEM micrographs. From the I-V characteristics, the high photo response and photo detectivity and good external quantum efficiency of the photodetector based on $\mathrm{SnS}$ with oleic acid are appealing as a candidate material for photodetection application.

\section{Acknowledgment}

The Author (D. Thangaraju) sincerely thank Science and Engineering Research Board (ECR/2017/002974), Department of Science and Technology, Government of India, for the financial support. The Author (N.S.M.P. Latha Devi) would like to thank Department of Science and Technology (DST), Govt. of India, for the award of DST-FIST Level-1 (SR/FST/PS-1/2018/35) scheme to Department of Physics, KLEF.

\section{Declaration of interest}

Authors have no conflict of interest to declare in their current work.

\section{References}

[1] R. Karthikeyan, D. Thangaraju, N. Prakash, Y. Hayakawa, CrystEngComm 17, 5431 (2015)

[2] A. Kumar, P.R. Thakur, G. Sharma, M. Naushad, A. Rana, G.T. Mola, F.J. Stadler, Environ Chem Lett. 17, 655 (2019)

[3] A.D. Martinez, A.N. Fioretti, E.S. Toberer, A.C. Tamboli, J. Mater. Chem. A 5, 11418 (2017)

[4] S.H. Yu, A. Jin, X. Huang, Y. Yang, R. Huang, J. D. Brock, Y.E. Sung, H.D. Abruña, RSC Adv. 8, 23847 (2018)

[5] B. Zhao, D. Song, Y. Ding, J. Wu, Z. Wang, Z. Chen, Y. Jiang, J. Zhang, Nanoscale 12, $3941(2020)$ 
[6] B. Subramanian, C. Sanjeev raja, M. Jayachandran, Mater. Chem. Phys. 71, 40 (2001)

[7] F. Lu, J. Yang, R. Li, N. Huo, Y. Li, Z. Wei, J. Li, J. Mater. Chem. C 3, 1397 (2015)

[8] X. Wang, W. Song, B. Liu, G. Chen, D. Chen, C. Zhou, G. Shen, Adv. Funct. Mater. 23, $1202(2013)$

[9] G. Chen, W. Wang, C. Wang, T. Ding, Q. Yang, Adv. Sci. 2, 1500109 (2015)

[10] P.K. Dutta, S. Mitra, Mater. Today 5, 23321 (2018)

[11] S.H. Chaki, M.D. Chaudhary , M.P. Deshpand, Adv. Nat. Sci. 5, 045010 (2014)

[12] H. Zhu, D. Yang, H. Zhang, Mater. Lett. 60, 2686 (2006)

[13] A. Manthiram, J. Phys. Chem. Lett. 2, 176 (2011)

[14] Y. Liu, D. Hou, G. Wang, Chem. Phys. Lett. 379, 67 (2003)

[15] G. Shen, D. Chen, K. Tang, L. Huang, Y. Qian, G. Zhou, Inorg. Chem. Commun. 6, 178 (2003)

[16] R.E. Abutbul, E. Segev, L. Zeiri, V. Ezersky, G. Makov, Y. Golan, RSC Adv. 6, 5848 (2016)

[17] D.S. Koktysh, J.R. McBride, S.J. Rosenthal, Nanoscale Res. Lett. 2, 144 (2007)

[18] J.Ning, K.Men, G.Xiao, L.Wang, Q.Dai, B.Zou, B.Liu, G.Zou, Nanoscale 2, 1699 (2010)

[19] S. Biswas, S. Kar, S. Chaudhuri, Appl. Surf. Sci. 253, 9259 (2007)

[20] K.N. Manukumar, G. Nagaraju, B. Kishore, C. Madhu, N. Munichandraiah, J. Energy Chem.27, 806 (2018)

[21] T. Jiang, G.A. Ozin, J. Mater. Chem. 8, 1099 (1998)

[22] A. Tanusevski, Semicond. Sci. Technol. 18, 501 (2003)

[23] S.R. Kadam, S. Ghosh, R.B. Ziv, M.B. Sadan, Eur. J. Chem. 26, 6679 (2020)

[24] D.H. Youn, S.K. Stauffer, P. Xiao, H. Park, Y. Nam, A. Dolocan, G. Henkelman, A. Heller, C.B. Mullins, ACS Nano. 10, 1210778 (2016)

[25] S. Kabouche, B. Bellal, Y. Louafi, M. Trari, Mater. Chem. Phys. 195, 229 (2017)

[26] M. S Mahdi, H.S. Al-Arab, K.H. Latif, K. Ibrahim, M. Bououdin, Appl. Phys. A. 126, 958 (2020)

[27] J. Chao, Z. Wang, X. Xu, Q. Xiang, W. Song, G. Chen, J. Hu, D. Chen, RSC Adv. 3, $2746(2013)$

[28] Z. Xie, D. Wang, T. Fan, C. Xing, Z. Li, W. Tao, L. Liu, S. Bao, D. Fan, H. Zhang, J Mater Chem. B. 6, 4747 (2018)

[29] B. Yang, X. Zuo, P. Chen, L. Zhou, X. Yang, H. Zhang, G. Li, M. Wu, Y. Ma, S. Jin, X. Chen, ACS Appl. Mater. Interfaces. 7, 137 (2015) 
[30] M.S. Mahdi, K. Ibrahim, N.M. Ahmed, A. Hmood, S.A. Azzez, Solid State Phenom. 290, 220 (2019)

[31] X. Zhou, L. Gan, Q. Zhang, X. Xiong, H. Li, Z. Zhong, J. Han, T. Zhai, J. Mater. Chem. C. 4, 2111 (2016)

[33] T. Srinivasa Reddy, M.C. Santhosh Kumar, RSC Adv. 6, 95680 (2016)

[34] S.H. Chaki, M.D. Chaudhary, M.P. Deshpande, Adv. Nat. Sci. 5, 045010 (2014)

[35] S. Gunasekaran, D. Thangaraju, R. Marnadu, J. Chandrasekaran, T. Alshahrani, M. Shkir, A. Durairajan, M.P.F. Graça, M. Elango, Surf. Interfaces 20, 100622 (2020)

[36] V. Balasubramani, J. Chandrasekaran, R. Marnadu, P. Vivek, S. Maruthamuthu, S. Rajesh, J InorgOrganometPolym Mater. 29, 1533 (2019)

[37] S. Gunasekaran, D. Thangaraju, R. Marnadu, J. Chandrasekaran, M. Shkird, A. Durairajan, M.A. Valente, T. Alshaharani, M. Elango, Sensor Actuat A-Phys. 317, 112373 (2021)

[38] R. Marnadu, J. Chandrasekaran, M. Raja, M. Balaji, S. Maruthamuthu, P. Balraju, Superlattices Microstruct. 119, 134 (2018)

[39] H. Tian, C. Fan, G. Liu, S. Yuan, Y. Zhang, M.Wang, E. Li, Appl. Surf. 487, 1043 (2019)

[40] D Thangaraju, R Marnadu, V Santhana, A Durairajan, P Kathirvel, J Chandrasekaran, S Jayakumar, MA Valente, Darius C Greenidge, CrystEngComm, 22, 525 (2020)

[41] G. Liu, Y. Li, B. Li, H. Tian, C. Fan, Y. Zhang, Z. Hua, M. Wang, H. Zheng, E. Li, J. Mater. Chem. C 6, 10036 (2018) 


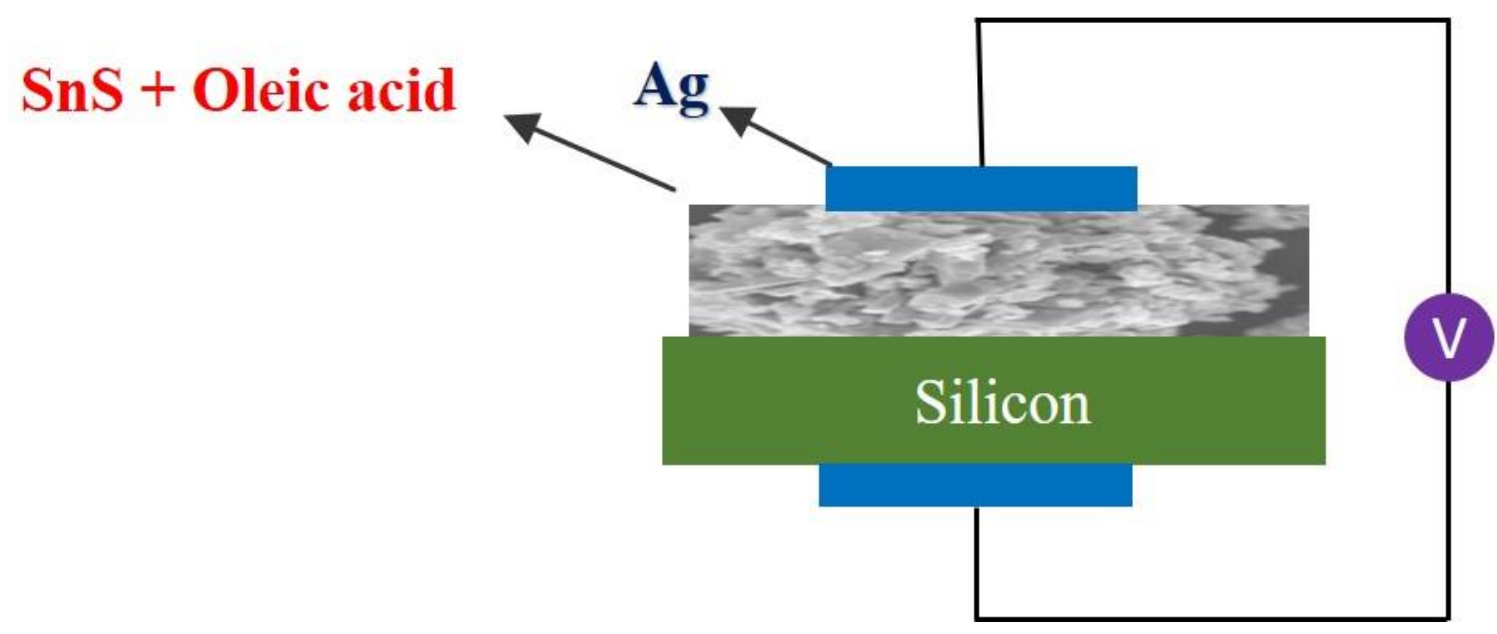

Fig. 1. Schematic diagram of $\mathrm{SnS}+$ Oleic acid-based photodiode 


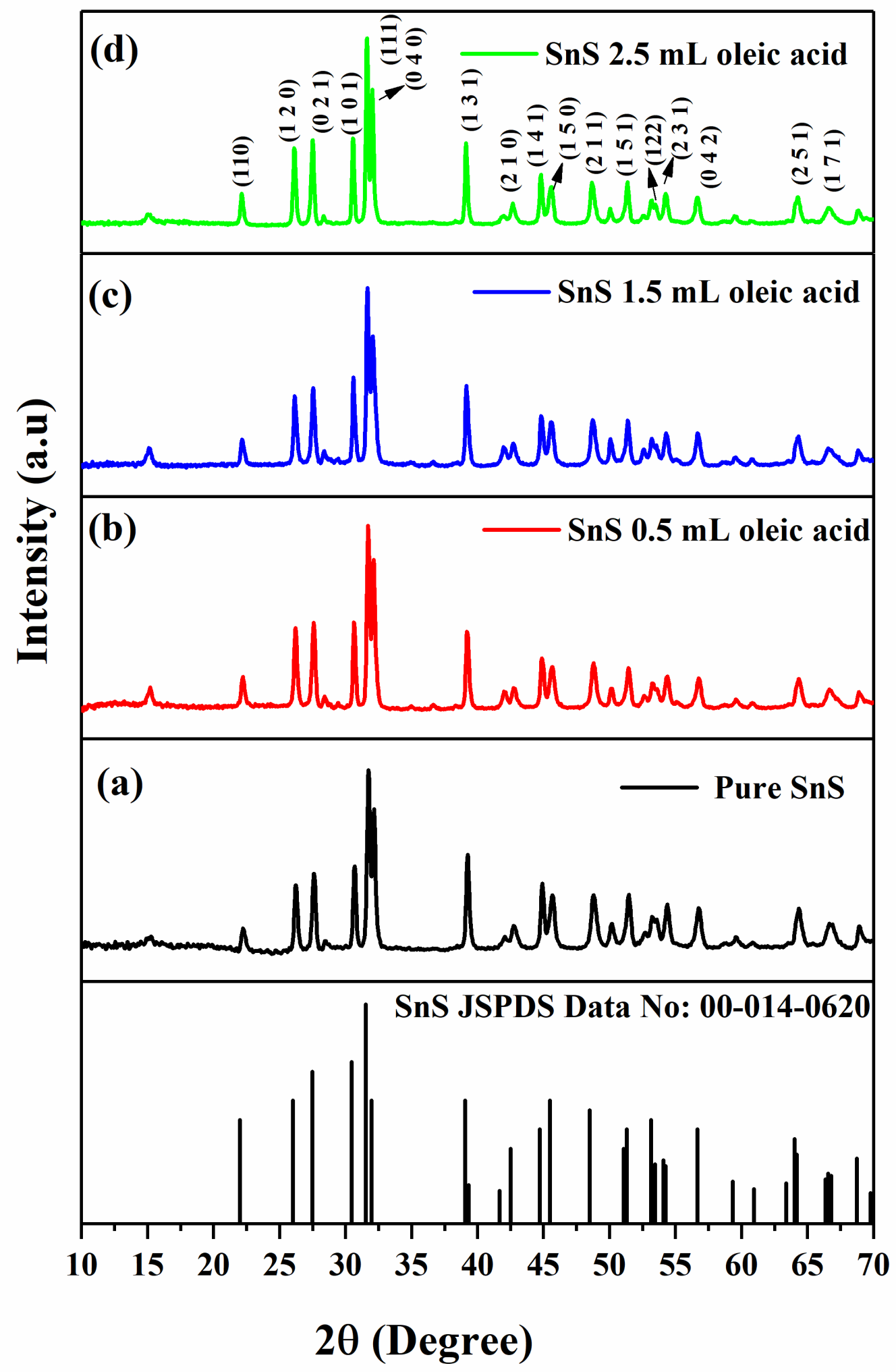

Fig. 2. XRD pattern of (a) Pure $\mathrm{SnS}$, (b) $\mathrm{SnS}+$ oleic acid $(0.5 \mathrm{~mL})$, (c) $\mathrm{SnS}+$ oleic acid $(1.5 \mathrm{~mL})$, and $(\mathrm{d}) \mathrm{SnS}+$ oleic acid $(2.5 \mathrm{~mL})$ 


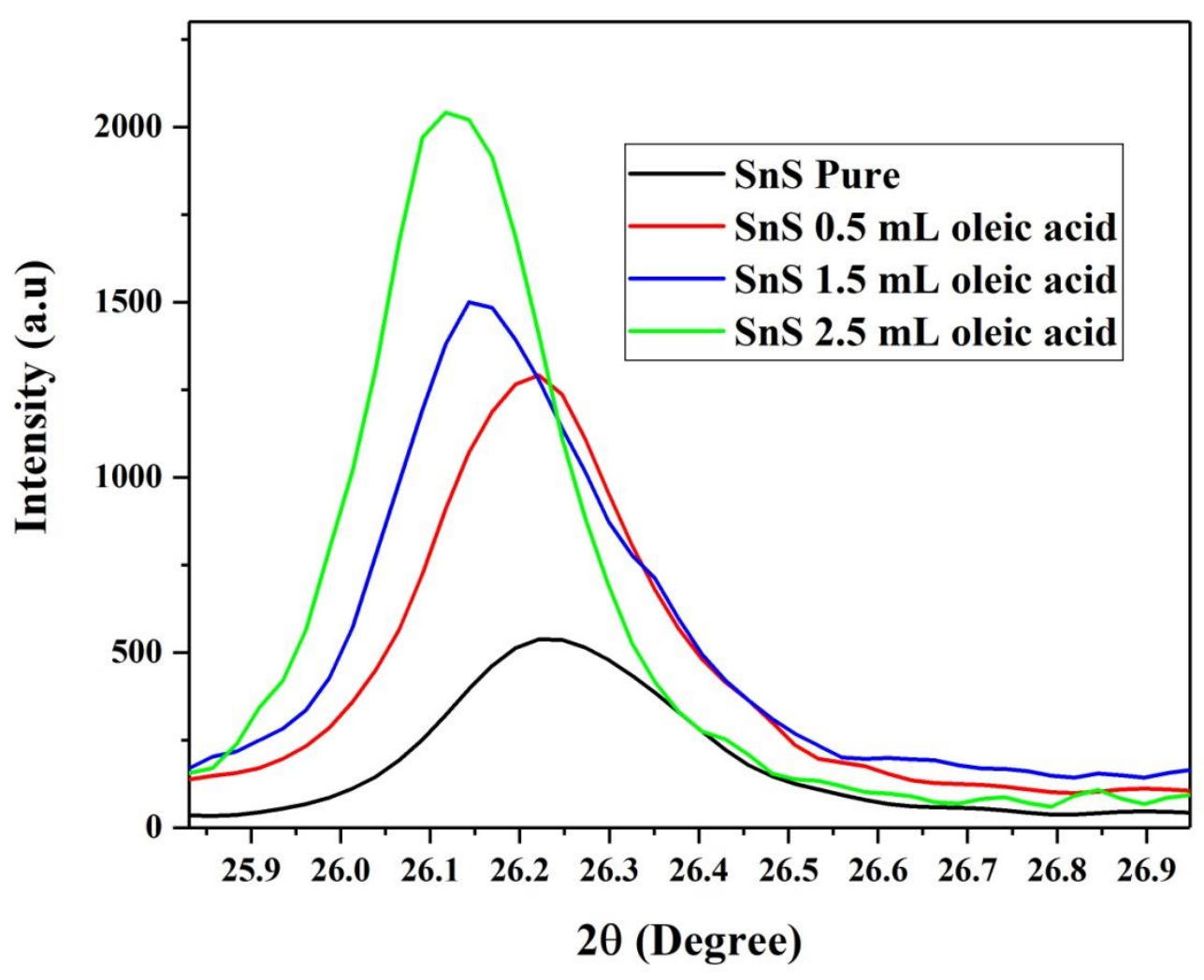

Fig. 3. Comparison of variation in intensity of (a) Pure $\mathrm{SnS}$, (b) $\mathrm{SnS}+$ oleic acid (0.5mL), (c) $\mathrm{SnS}+$ oleic acid (1.5mL), and (d) $\mathrm{SnS}+$ oleic acid (2.5mL) 


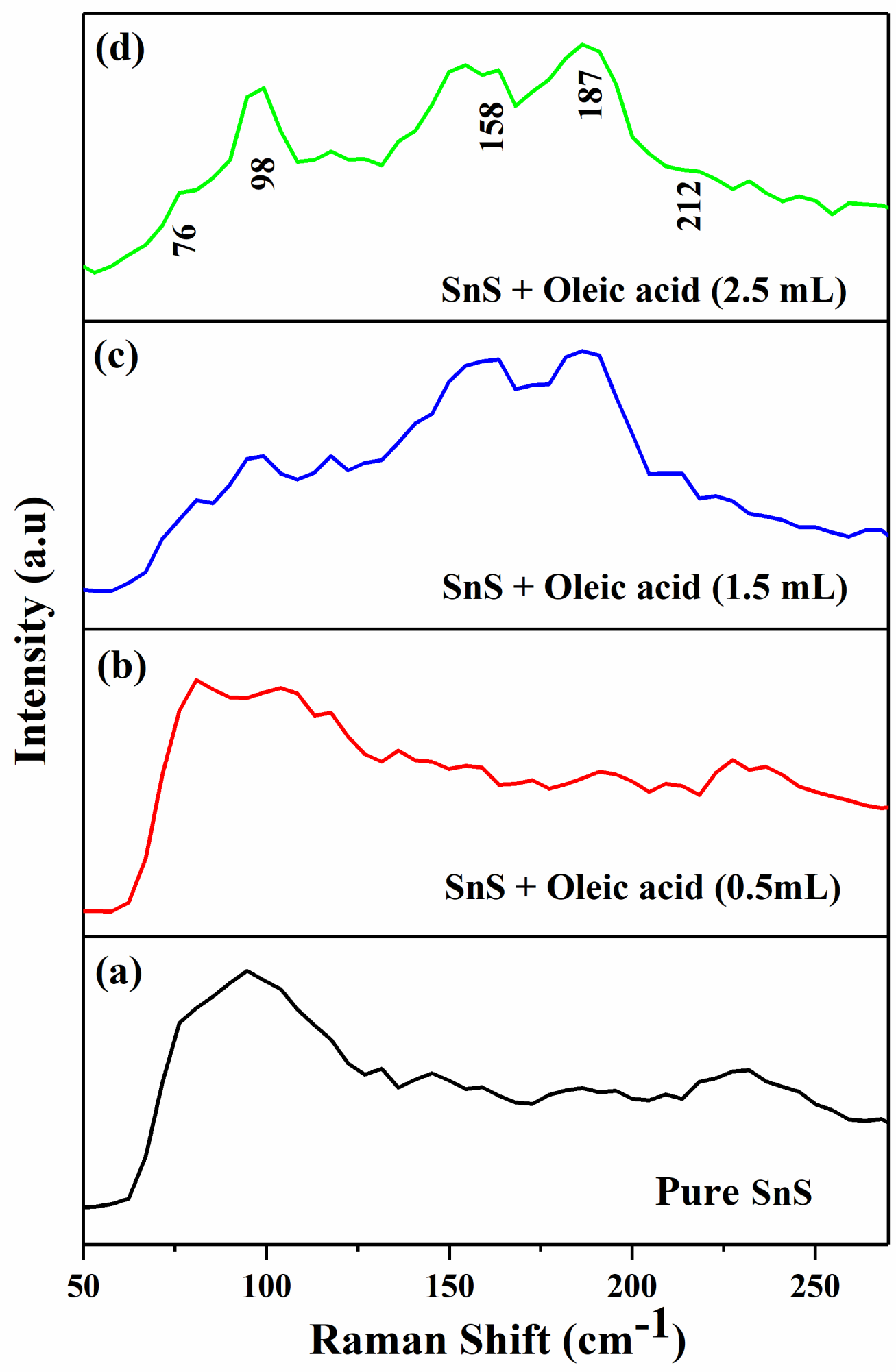

Fig. 4. The Raman spectra of (a) Pure $\mathrm{SnS}$, (b) $\mathrm{SnS}+$ oleic acid (0.5 mL), (c) $\mathrm{SnS}+$ oleic acid (1.5 mL), and (d) $\mathrm{SnS}+$ oleic acid $(2.5 \mathrm{~mL})$ 

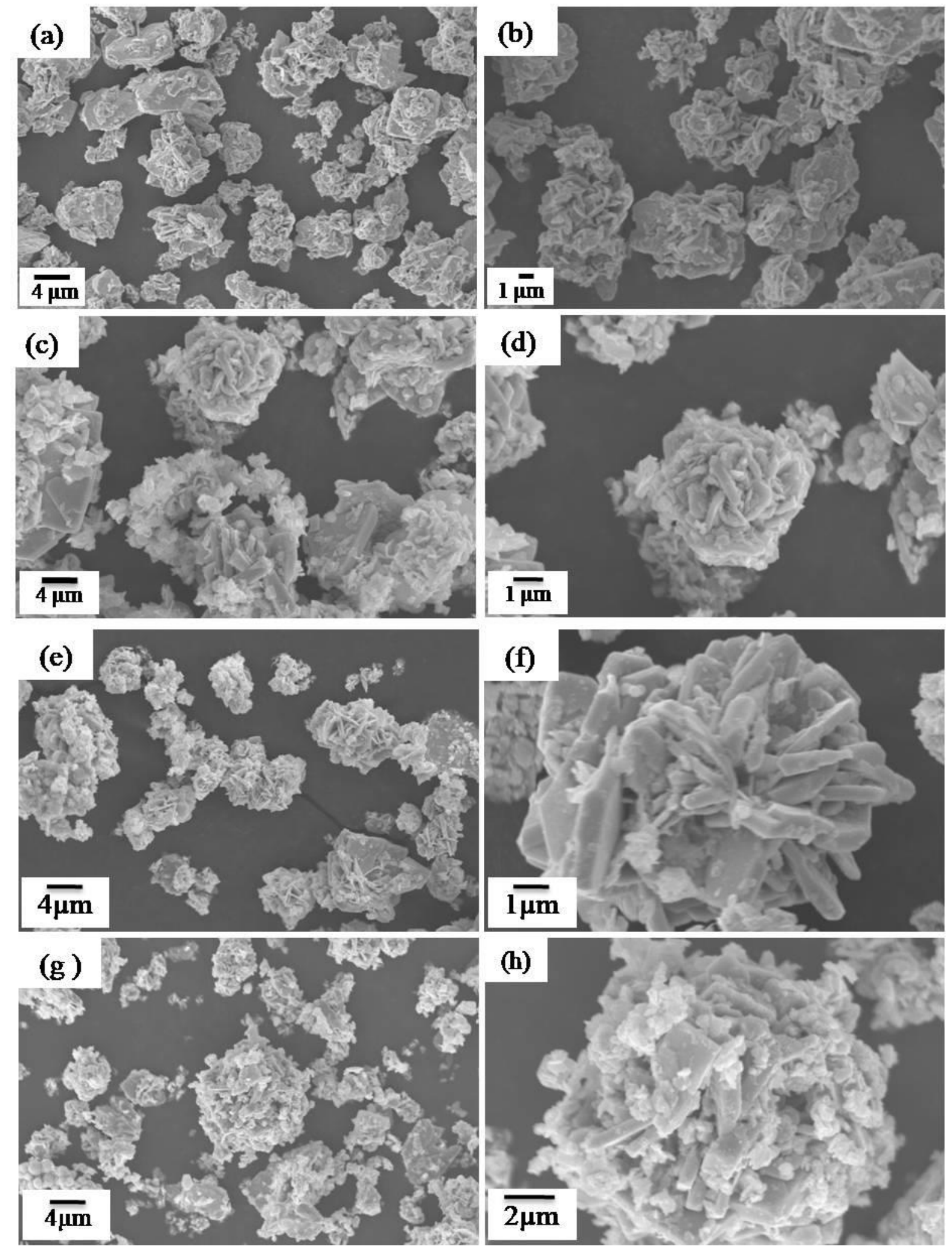

Fig. 5. FESEM images of (a) Pure $\mathrm{SnS}$, (b) $\mathrm{SnS}+$ oleic acid (0.5 mL), (c) $\mathrm{SnS}+$ oleic acid $(1.5 \mathrm{~mL})$, and $(\mathrm{d}) \mathrm{SnS}+$ oleic acid $(2.5 \mathrm{~mL})$ 

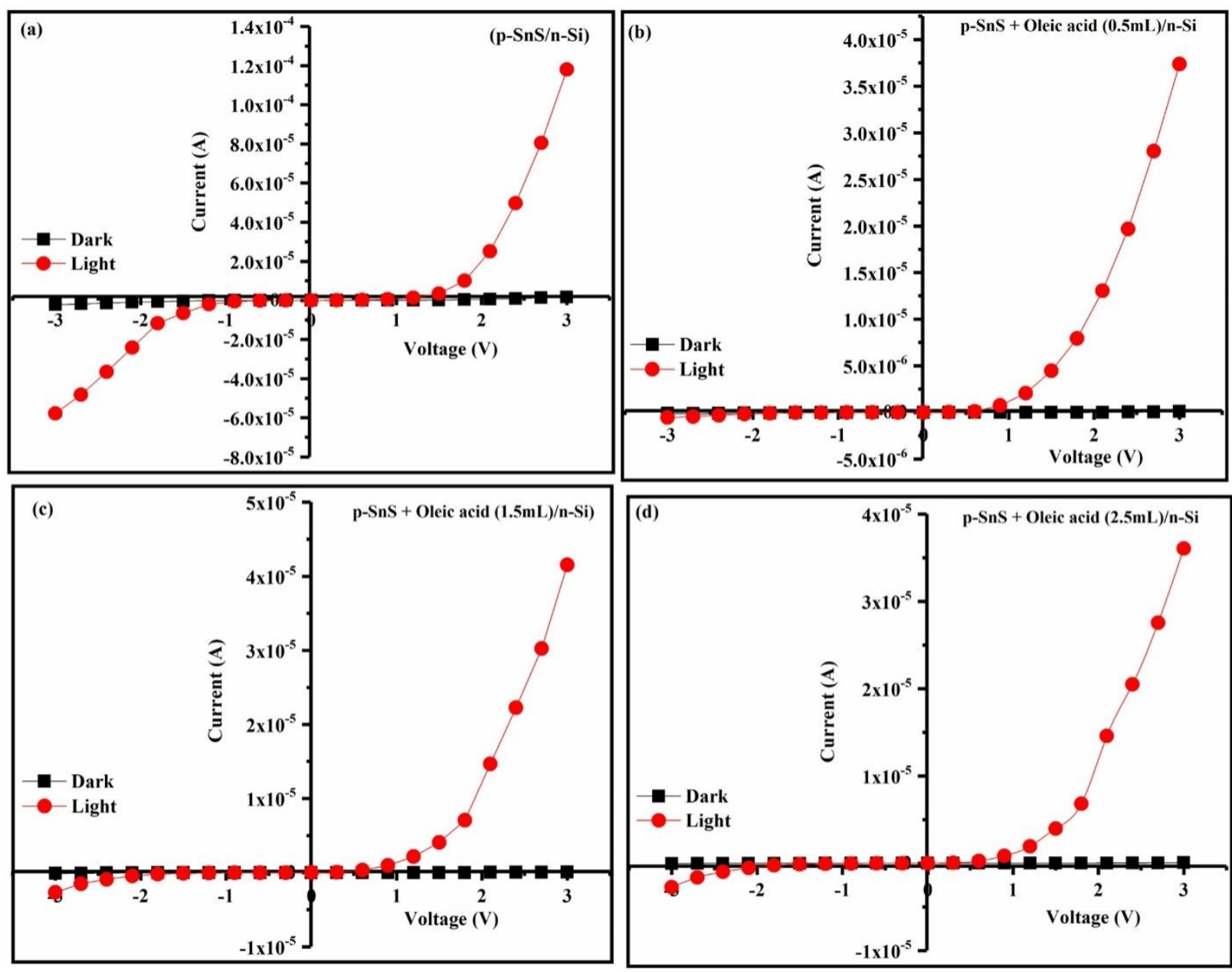

Fig. 6. I-V characteristics of(a) Pure $\mathrm{SnS}$, (b) $\mathrm{SnS}+$ oleic acid (0.5mL), (c) $\mathrm{SnS}+$ oleic acid (1.5mL), (d) $\mathrm{SnS}+$ oleic acid (2.5mL) 

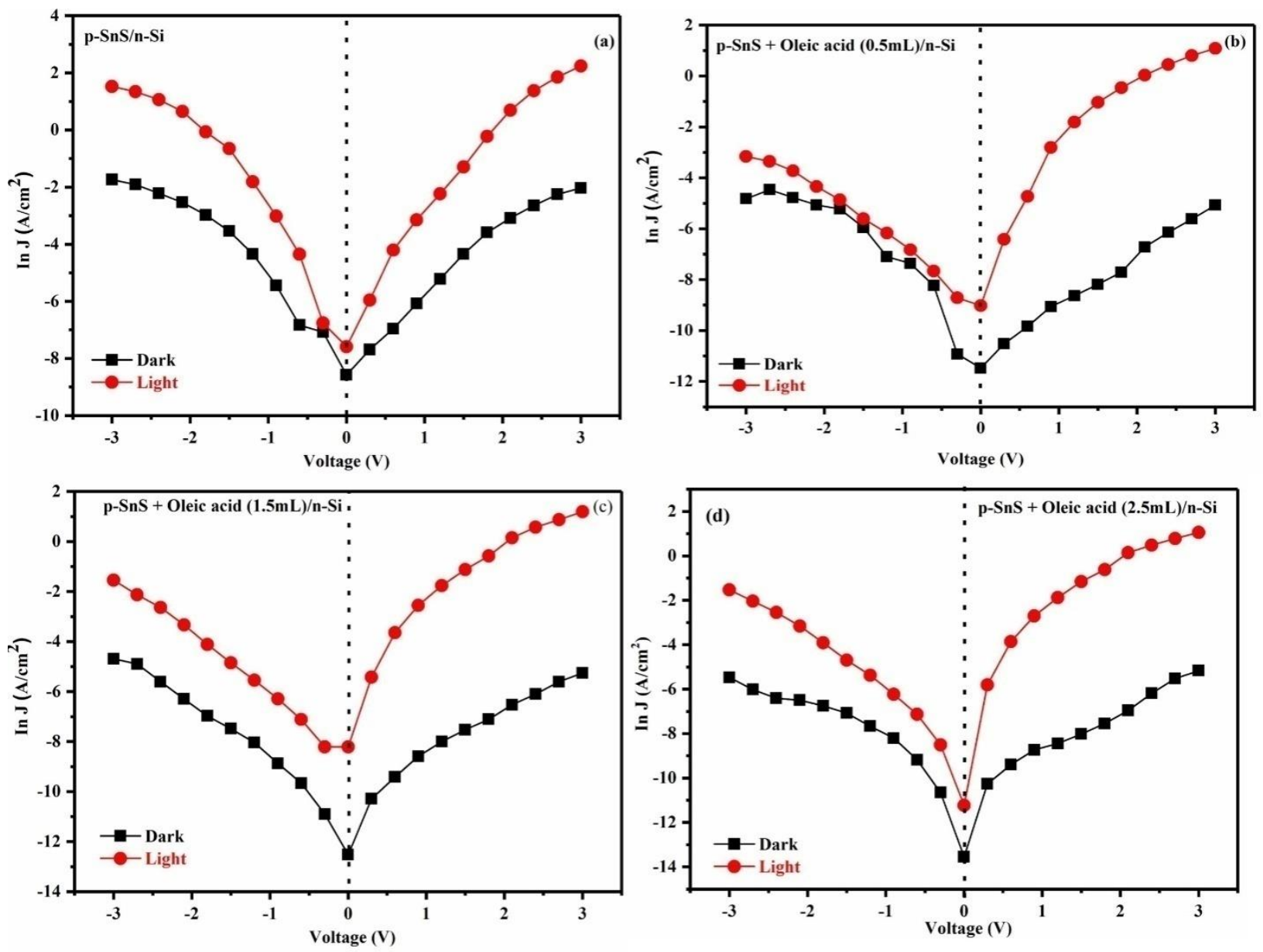

Fig. 7. Semi-logarithmic plot of $\ln (\mathrm{J})$ vsV of (a) Pure $\mathrm{SnS}$, (b) $\mathrm{SnS}+$ oleic acid (0.5 mL), (c) $\mathrm{SnS}+$ oleic acid $(1.5 \mathrm{~mL})$, and $(\mathrm{d}) \mathrm{SnS}+$ oleic acid $(2.5 \mathrm{~mL})$ 

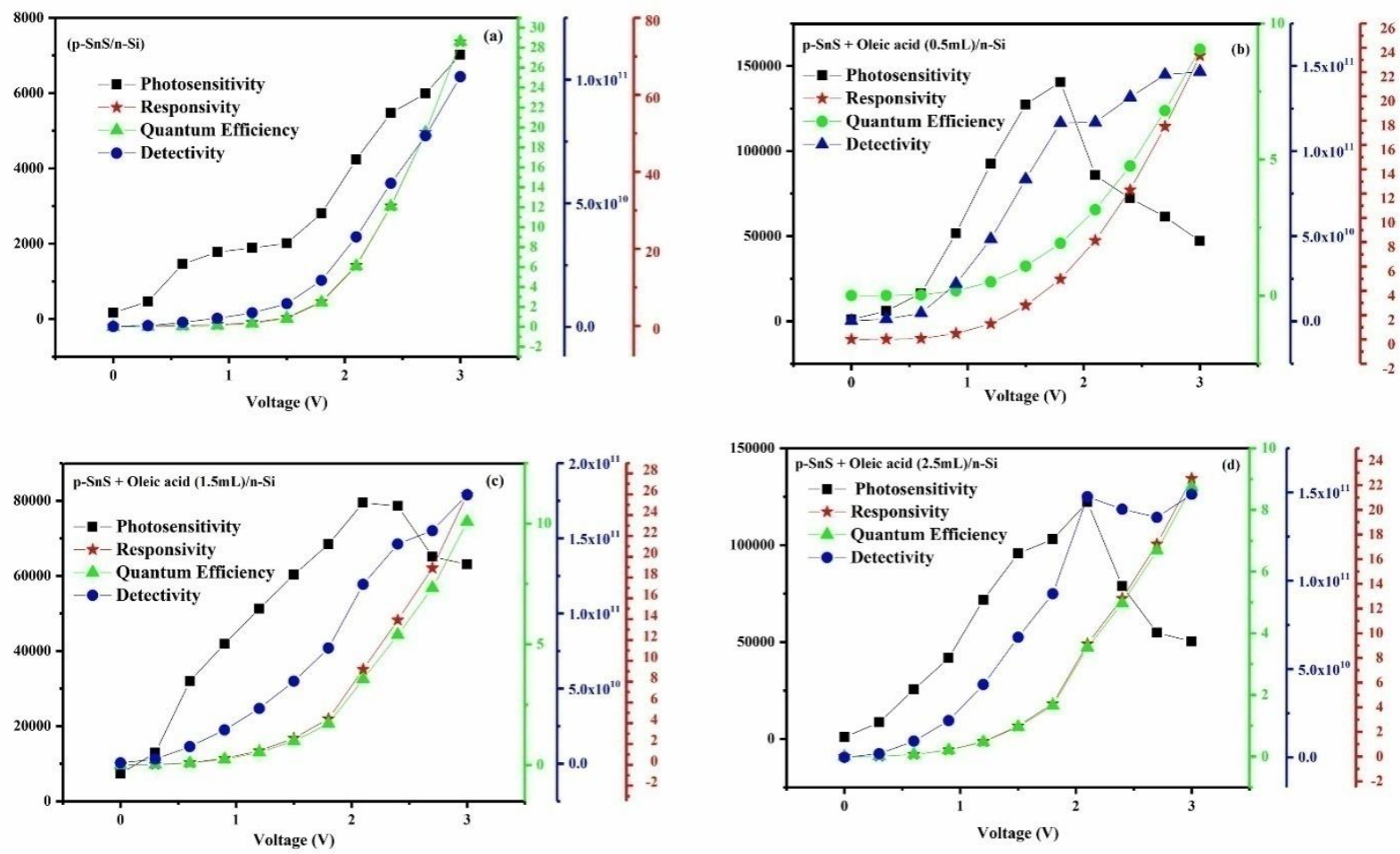

Fig. 8. Comparative plot of Ideality factor (n), Barrier height $\left(\Phi_{\mathrm{B}}\right)$, Photosensitivity (Ps), Photoresponsivity (R), Quantum efficiency (QE) \%, Specific detectivity (D*) vs Voltage graph of (a) Pure SnS, (b) $\mathrm{SnS}+$ oleic acid $(0.5 \mathrm{~mL})$, (c) $\mathrm{SnS}+$ oleic acid (1.5 mL), and (d) $\mathrm{SnS}+$ oleic acid $(2.5 \mathrm{~mL})$ 
Table 1: Photodiode parameter of $\mathrm{p}-\mathrm{SnS} / \mathrm{n}-\mathrm{Si}, \mathrm{p}-\mathrm{SnS}+$ Oleic acid $(0.5 \mathrm{~mL}) / \mathrm{n}-\mathrm{Si}), \mathrm{p}-\mathrm{SnS}+$ Oleic acid $(1.5 \mathrm{~mL}) / \mathrm{n}-\mathrm{Si}), \mathrm{p}-\mathrm{SnS}+$ Oleic acid $(2.5 \mathrm{~mL}) / \mathrm{n}-\mathrm{Si})$ based diode such as Ideality factor (n), Barrier height $\left(\Phi_{\mathrm{B}}\right)$, Photosensitivity $\left(\mathrm{P}_{\mathrm{S}}\right)$, Photoresponsivity (R), Quantum efficiency $(\mathrm{QE}) \%$, Specific detectivity $\left(\mathrm{D}^{*}\right)$.

\begin{tabular}{|c|c|c|c|c|c|c|c|c|}
\hline \multirow{2}{*}{ Diode } & \multicolumn{2}{|c|}{$\begin{array}{l}\text { Ideality factor } \\
\text { (n) }\end{array}$} & \multicolumn{2}{|c|}{$\begin{array}{c}\text { Barrier height } \\
\Phi_{\mathrm{B}}(\mathrm{eV})\end{array}$} & \multirow{2}{*}{$\begin{array}{c}\text { Photo } \\
\text { Sensitivity } \\
\text { Ps }(\%)\end{array}$} & \multirow{2}{*}{$\begin{array}{c}\text { Photo } \\
\text { Responsivity } \\
\text { R (mA/W) }\end{array}$} & \multirow{2}{*}{$\begin{array}{c}\text { Quantum } \\
\text { Efficiency } \\
\text { QE }(\%)\end{array}$} & \multirow{2}{*}{$\begin{array}{c}\text { Specific } \\
\text { Detectivity } \\
\mathrm{D}\left(\times 10^{10}\right) \\
(\text { Jone })\end{array}$} \\
\hline & Dark & Light & Dark & Light & & & & \\
\hline $\mathrm{p}-\mathrm{SnS} / \mathrm{n}-\mathrm{Si}$ ) & 12.7 & 6.7 & 0.70 & 0.67 & 7018.02 & 73.75 & 28.5 & $\begin{array}{c}1.01194 \times 10 \\
11\end{array}$ \\
\hline $\begin{array}{c}\mathrm{p}-\mathrm{SnS}+\text { Oleic acid } \\
(0.5 \mathrm{~mL}) / \mathrm{n}-\mathrm{Si})\end{array}$ & 9.5 & 4.4 & 0.78 & 0.71 & 47089.0 & 23.3 & 9.0 & $\begin{array}{l}1.46602 \times 10 \\
11\end{array}$ \\
\hline $\begin{array}{c}\mathrm{p}-\mathrm{SnS}+\text { Oleic acid } \\
(1.5 \mathrm{~mL}) / \mathrm{n}-\mathrm{Si})\end{array}$ & 5.2 & 4.2 & 0.81 & 0.69 & 63095.6 & 25.97 & 10.07 & $1.7893 \times 10^{11}$ \\
\hline $\begin{array}{c}\mathrm{p}-\mathrm{SnS}+\text { Oleic acid } \\
(2.5 \mathrm{~mL}) / \mathrm{n}-\mathrm{Si})\end{array}$ & 2.0 & 3.4 & 0.83 & 0.77 & 50301.9 & 22.5 & 8.7 & $\underset{11}{1.48888 \times 10}$ \\
\hline
\end{tabular}


Figures

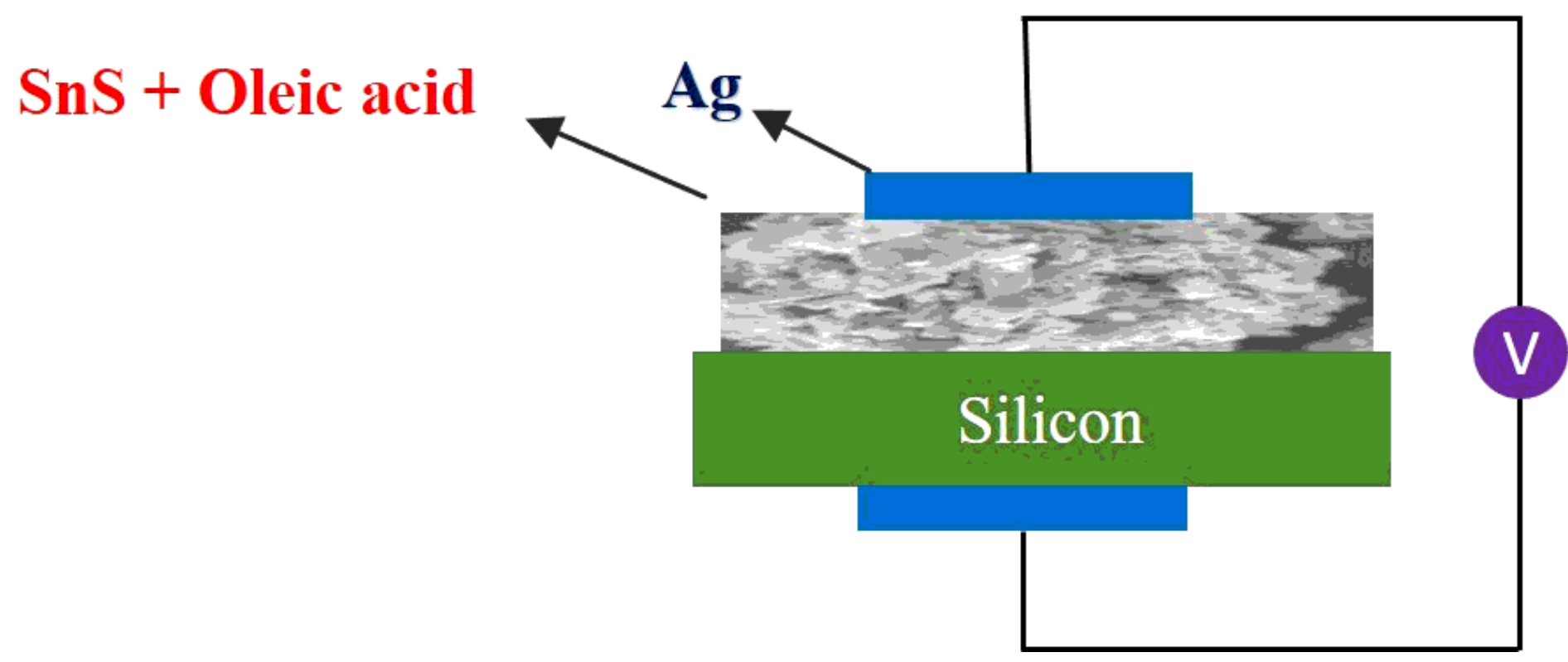

Figure 1

Schematic diagram of SnS + Oleic acid-based photodiode 


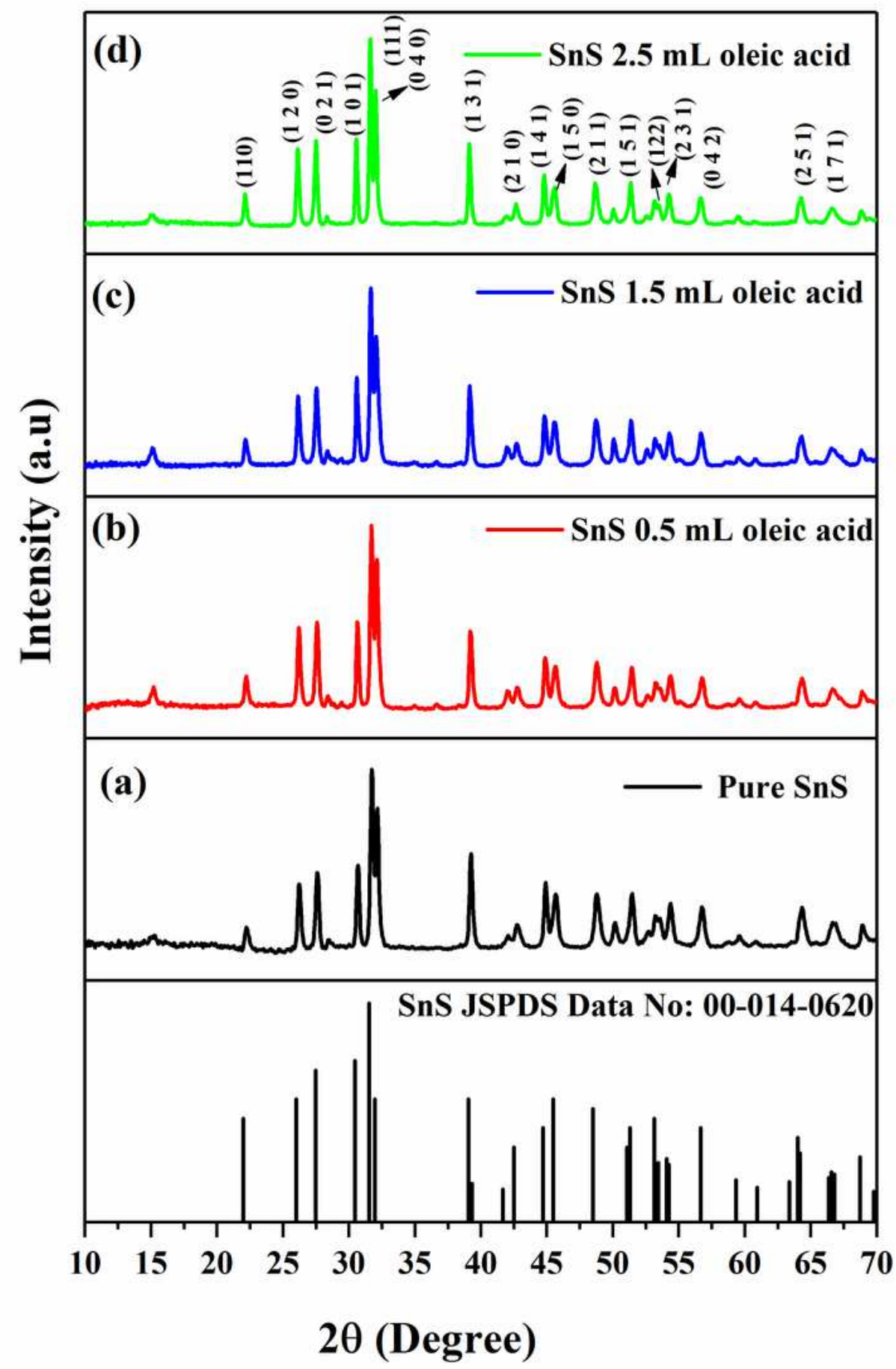

Figure 2

XRD pattern of (a) Pure SnS, (b) SnS + oleic acid (0.5mL), (c) SnS + oleic acid (1.5mL), and (d) SnS + oleic acid $(2.5 \mathrm{~mL})$ 


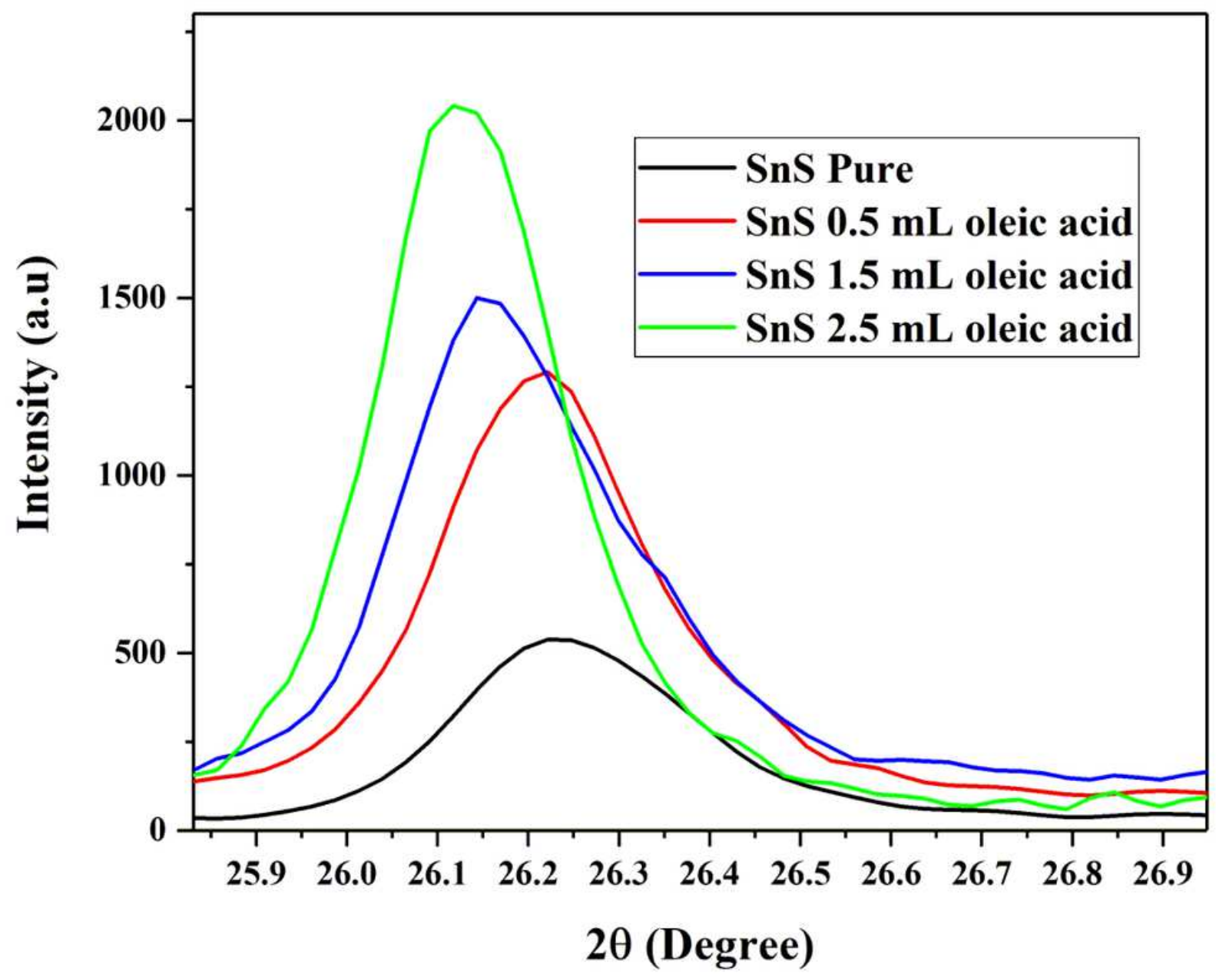

Figure 3

Comparison of variation in intensity of (a) Pure SnS, (b) SnS + oleic acid (0.5mL), (c) SnS + oleic acid $(1.5 \mathrm{~mL})$, and $(\mathrm{d}) \mathrm{SnS}+$ oleic acid $(2.5 \mathrm{~mL})$ 


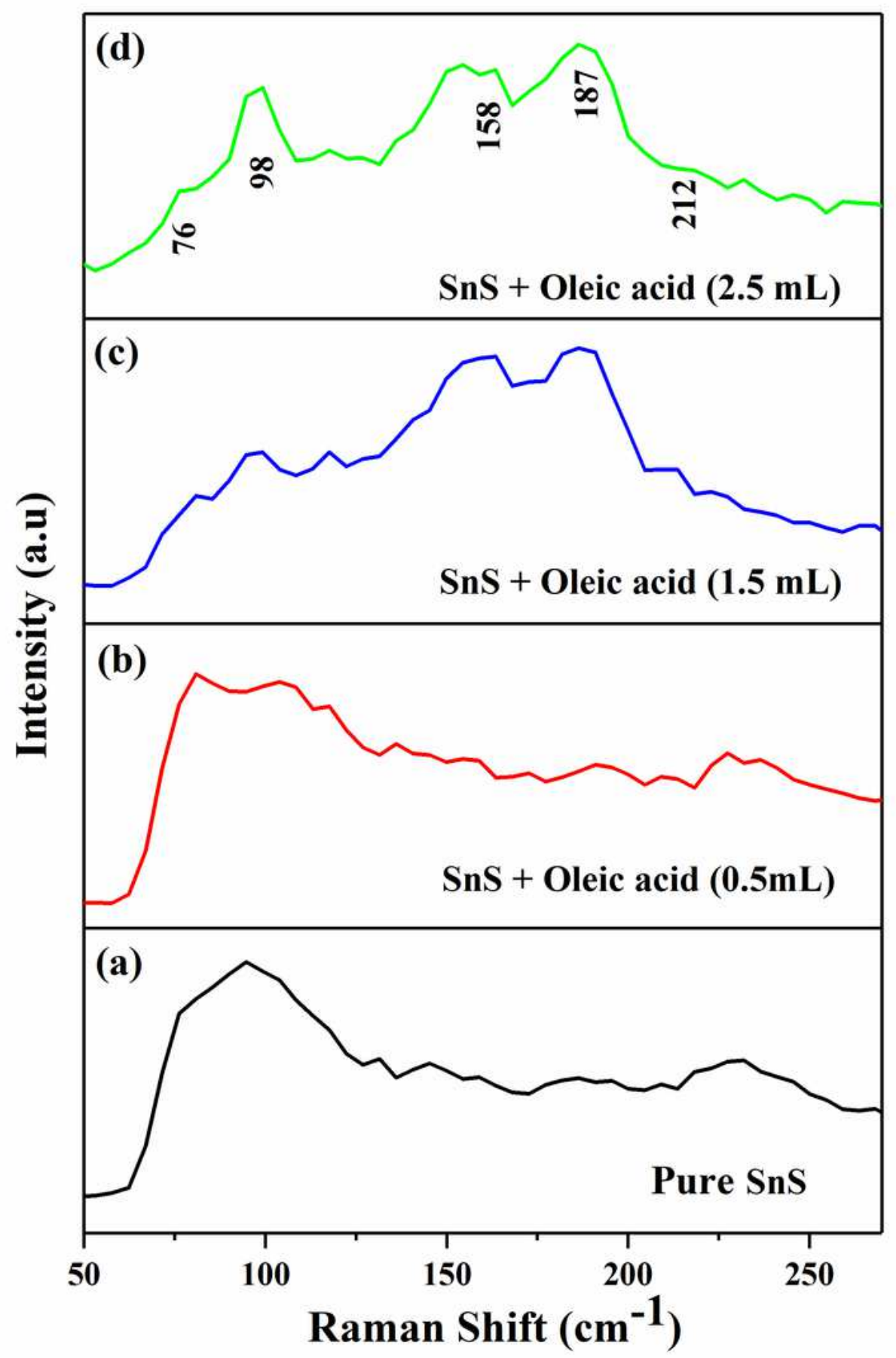

Figure 4

The Raman spectra of (a) Pure SnS, (b) SnS + oleic acid (0.5 mL), (c) SnS + oleic acid (1.5 mL), and (d) SnS + oleic acid $(2.5 \mathrm{~mL})$ 

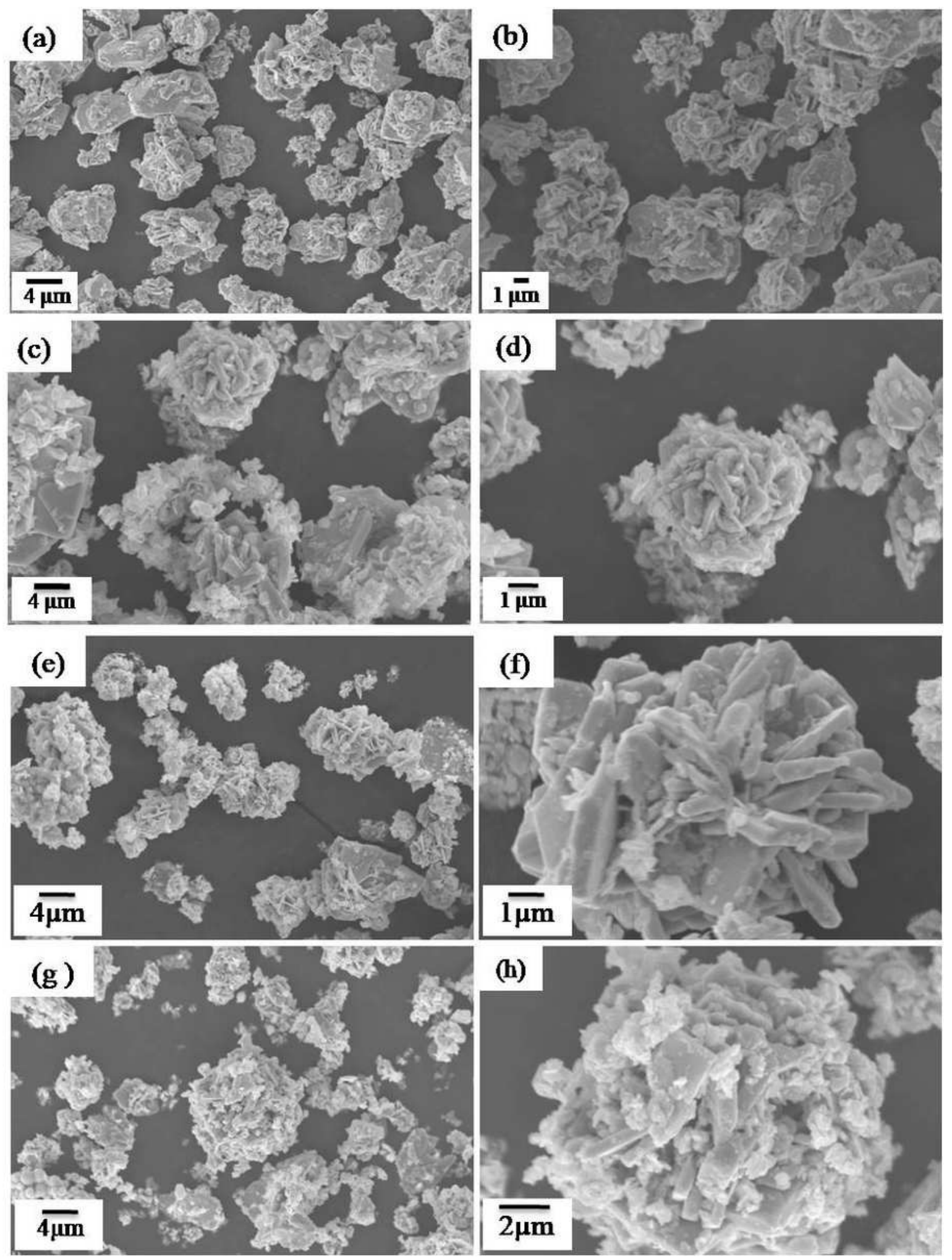

Figure 5

FESEM images of (a) Pure SnS , (b) SnS + oleic acid (0.5 mL), (c) SnS + oleic acid (1.5 mL), and (d) SnS + oleic acid $(2.5 \mathrm{~mL})$ 

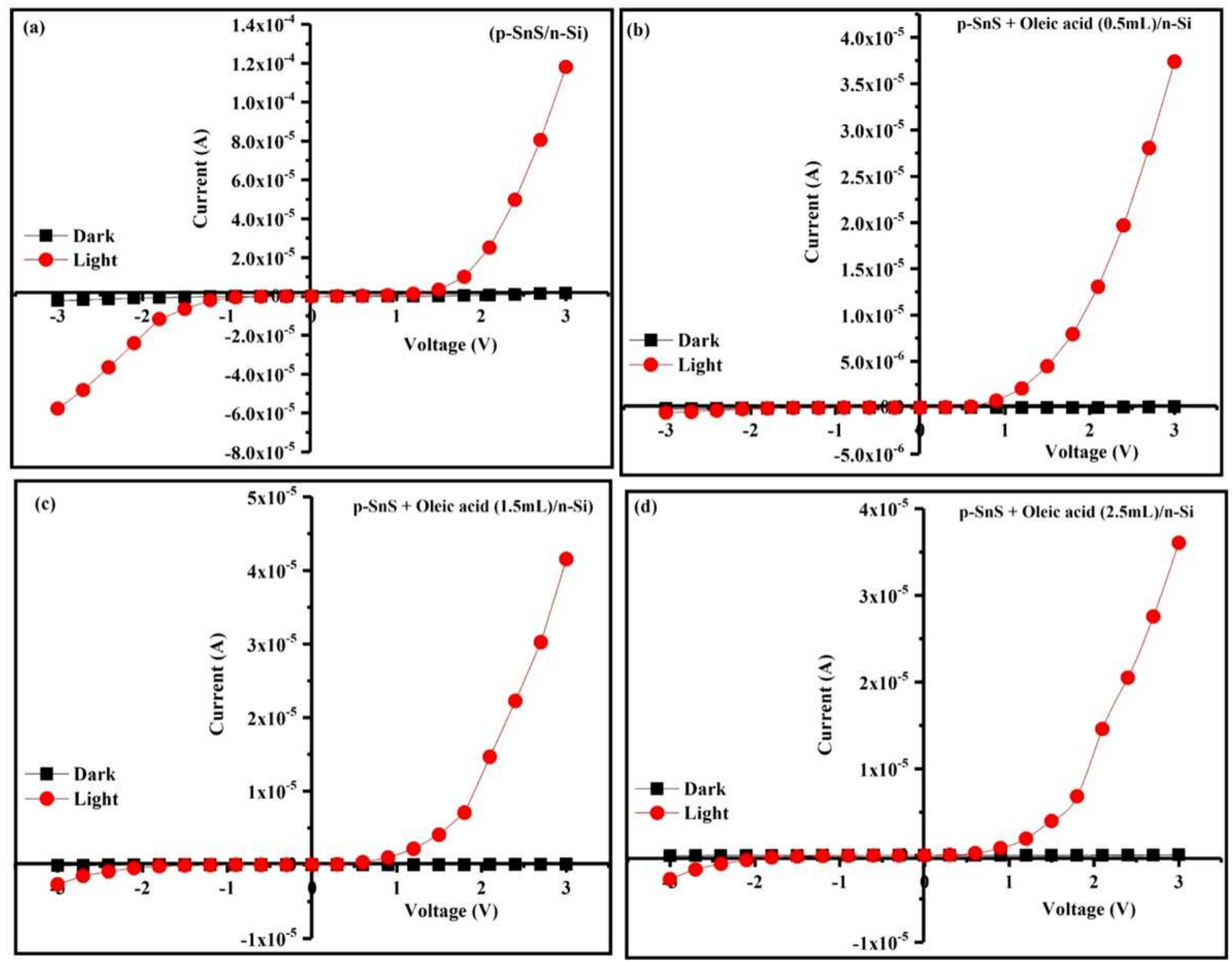

Figure 6

I-V characteristics of(a) Pure SnS, (b) SnS + oleic acid (0.5mL), (c)SnS + oleic acid (1.5mL), (d) SnS + oleic acid $(2.5 \mathrm{~mL})$ 

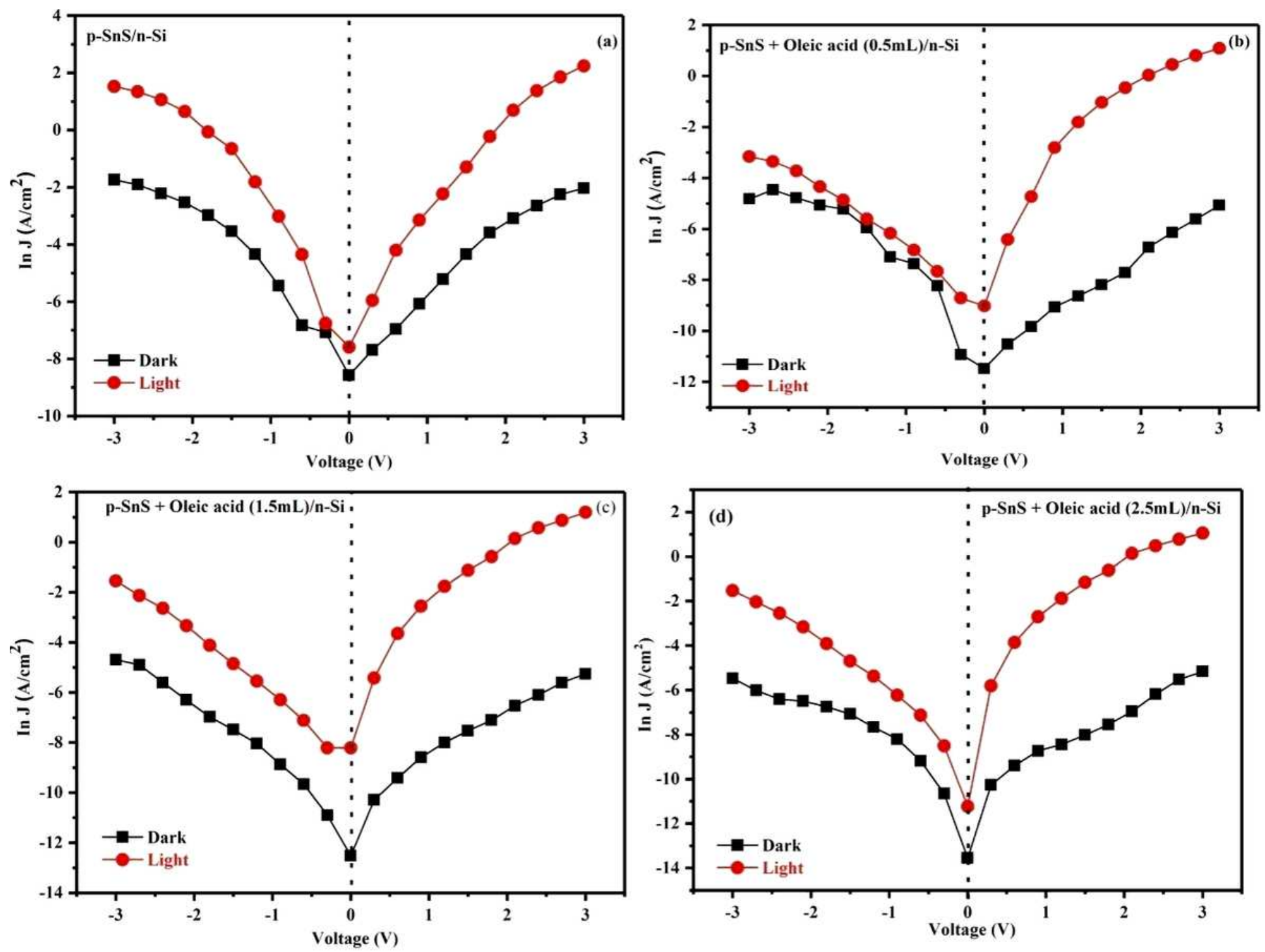

Figure 7

Semi-logarithmic plot of In (J) vsV of (a) Pure SnS, (b) SnS + oleic acid (0.5 mL), (c) SnS + oleic acid (1.5 $\mathrm{mL})$, and (d) SnS + oleic acid $(2.5 \mathrm{~mL})$ 

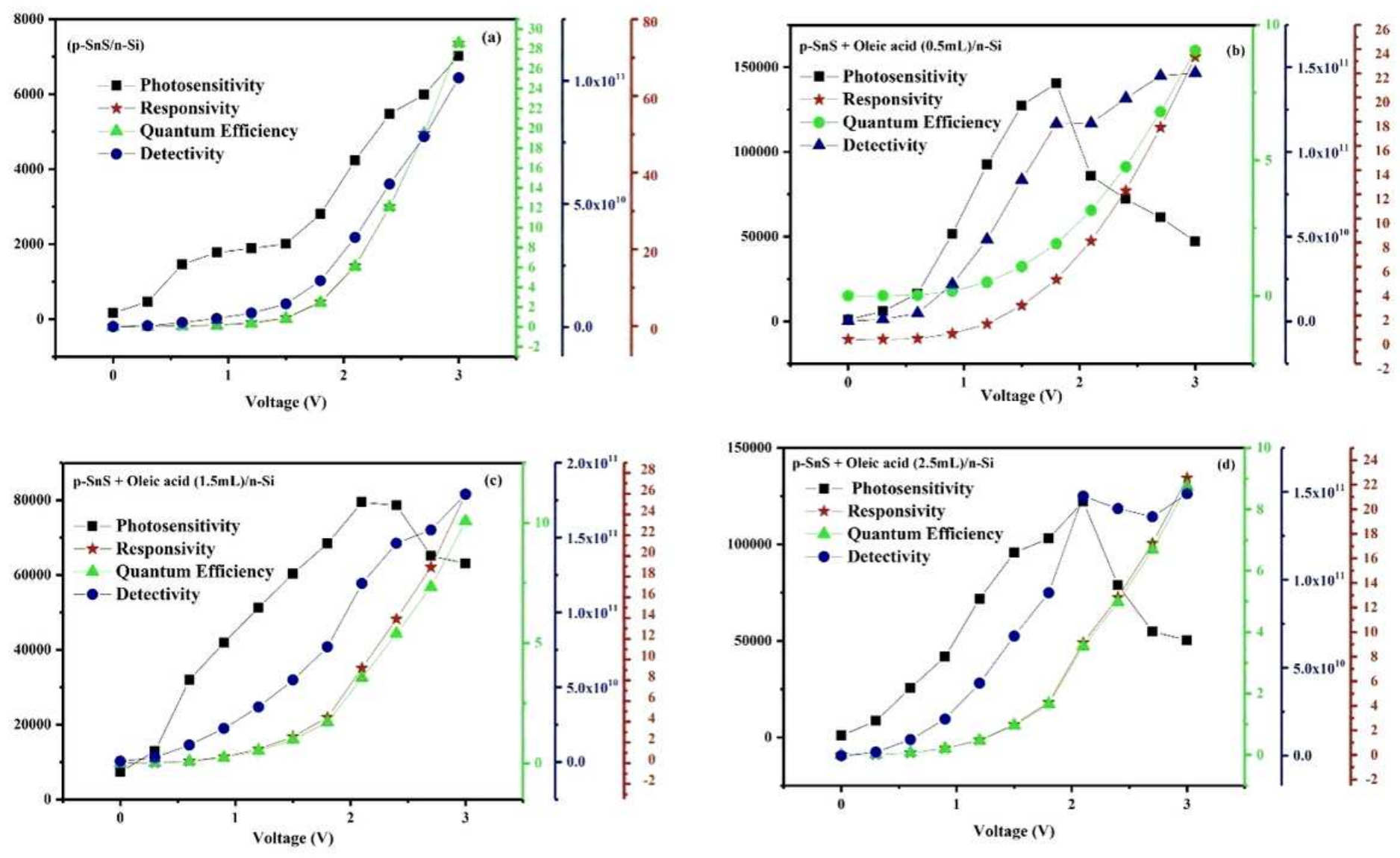

\section{Figure 8}

Comparative plot of Ideality factor (n), Barrier height (ФB), Photosensitivity (PS), Photoresponsivity (R), Quantum efficiency (QE) \%, Specific detectivity ( $\left.D^{*}\right)$ vs Voltage graph of (a) Pure SnS, (b) SnS + oleic acid $(0.5 \mathrm{~mL}),(\mathrm{c}) \mathrm{SnS}+$ oleic acid $(1.5 \mathrm{~mL})$, and (d) SnS + oleic acid $(2.5 \mathrm{~mL})$ 